\title{
Nile perch distribution in south-east Lake Victoria is more strongly driven by abiotic factors, than by prey densities
}

\author{
I. J. M. Cornelissen - P. A. M. van Zwieten • \\ H. K. Peter • L. A. J. Nagelkerke
}

Received: 29 October 2014/Revised: 18 February 2015/Accepted: 23 February 2015/Published online: 7 March 2015

(C) The Author(s) 2015. This article is published with open access at Springerlink.com

\begin{abstract}
We studied the effects of environmental driving factors (maximum depth, visibility, oxygen, temperature, and prey densities) on the distribution and diet composition of Nile perch (Lates niloticus) in south-east Lake Victoria from 2009 to 2011. We tested the hypotheses that (i) Nile perch distribution is regulated by the same environmental factors on a local scale (Mwanza Gulf) and on a regional scale (Mwanza Gulf, Speke Gulf and the open lake in Sengerema district), and (ii) driving factors act differently on different Nile perch size classes. Fish were sampled with gillnets. Nile perch densities were highest in the shallow part of the Mwanza Gulf and during the wet seasons, mainly caused by high densities of juveniles. The environmental driving factors explained Nile perch distributions on both regional and local scales in
\end{abstract}

Handling editor: Ivan Nagelkerken

I. J. M. Cornelissen - P. A. M. van Zwieten .

H. K. Peter · L. A. J. Nagelkerke ( $\square)$

Aquaculture and Fisheries Group, Wageningen

University, P.O. Box 338, 6700, AH, Wageningen,

The Netherlands

e-mail: leo.nagelkerke@wur.nl

\section{J. M. Cornelissen}

Netherlands Institute of Ecology (NIOO-KNAW),

P.O. Box 50, 6700, AB, Wageningen, The Netherlands

H. K. Peter

Tanzania Fisheries Research Institute (TAFIRI), P.O. Box 9750, Dar es Salaam, Tanzania a similar way, often showing non-linear relationships. Maximum depth and temperature were the best predictors of Nile perch densities. Prey densities of shrimp and haplochromines did not strongly affect Nile perch distributions, but did explain Nile perch diet on a local and regional scale. We conclude that abiotic variables drive Nile perch distributions more strongly than prey densities and that feeding takes place opportunistically.

Keywords Caridina $\cdot$ Diet $\cdot$ Distribution . Haplochromines · Water quality

\section{Introduction}

Nile perch, Lates niloticus (L.), was repeatedly introduced in Lake Victoria in the 1950s and 1960s to boost the fisheries (Pringle, 2005). Its explosive population growth during the mid-1980s concurred with the decline in biomass and species numbers of haplochromine cichlids, a major prey of Nile perch (Witte et al., 1992). From that time onward the Nile perch fishery thrived, peaking with an estimated annual yield of around 300,000 tons during the late 1980 s after which it fluctuated around 250,000 tons (Kolding et al., 2008, 2014).

Since the start of the fisheries concerns have been voiced that Nile perch stocks are declining and may collapse if fishing pressure will continue to increase 
(Mkumbo, 2002; Balirwa et al., 2003; Getabu et al., 2003; Ogutu-Ohwayo, 2004; Matsuishi et al., 2006; Mkumbo et al., 2007). However, stock assessments based on Nile perch catches and population size structure showed no signs of overfishing or long-term decline of the Nile perch stock, although, since the 1990s the stock shows short-term decadal fluctuations (Kolding et al., 2008).

Besides fishing, water quality may play an important role in Nile perch distribution. The increasing eutrophication of Lake Victoria caused degradation of water quality, resulting in an increase in phytoplankton biomass. This led to changes in visibility and oxygen content of the water (Hecky, 1993, 1994), while global climate change resulted in an increase of water temperatures in Lake Victoria with more than $1^{\circ}$ since the 1920s (Sitoki et al., 2010). In addition, it is hypothesized that prey density and availability may have profound effects on the size structure and distribution patterns of Nile perch (Goudswaard et al., 2011; Downing et al., 2013).

Although Nile perch is considered a visual hunter, decreased visibility as such is not shown to affect Nile perch distributions, since it is found from clear to turbid waters. Nile perch is also a generalized predator, feeding on different types of prey of a large size range. This is an advantage when prey encounter rates decrease because of reduced visibility (Seehausen et al., 2003; Hecky et al., 2010). However, Nile perch is absent in turbid waters such as swamps when oxygen levels become critical (Chapman et al., 2002).

Several studies showed the relationship of dissolved oxygen and Nile perch densities (Wanink et al., 2001; Chapman et al., 2002; Mkumbo, 2002; Balirwa et al., 2003; Paterson \& Chapman, 2009; Goudswaard et al., 2011; Njiru et al., 2012; Nyboer \& Chapman, 2013; Taabu-Munyaho et al., 2013). In Lake Victoria seasonal stratification of the water column results in decreased oxygen concentrations near the bottom, especially in deeper water. This hypoxia limits fish to utilize habitats and probably forces Nile perch to move up above the oxycline or to migrate to oxygenated shallow waters (Goudswaard et al., 2011; TaabuMunyaho et al., 2013). Experiments showed that Nile perch was relatively intolerant to hypoxia (Schofield $\&$ Chapman, 2000). Therefore, hypoxic waters can act as refugia for hypoxia-tolerant haplochromine species in swamps, wetlands, and deep water (Hecky, 1994; Chapman et al., 2002; Paterson \& Chapman, 2009;
Njiru et al., 2012) and for the freshwater shrimp Caridina nilotica (Roux) (Kaufman, 1992; Hecky, 1994; Njiru et al., 2012), both important prey for Nile perch. Hypoxia also affects the size class distribution of fish, because it can limit physical growth and reproduction, resulting in a reduction of maximum fish size and length at maturity (Pauly, 1981, 1984). Furthermore, large-sized Nile perch are affected more by low oxygen than small-sized Nile perch, because of their smaller gill surface area to biomass ratio (Njiru et al., 2012). Sudden upwelling of anoxic waters caused incidental massive kills of large-sized Nile perch in Kenyan waters and in the Mwanza Gulf in the 1980s (Ochumba, 1990; Kaufman, 1992; Wanink et al., 2001) and fish kills of Nile perch at smaller scales (i.e., individual fish floating dead or gasping for air rather than groups of fish) have been observed in 2009-2011 on at least three occasions during the breakdown of stratification (I. J. M. Cornelissen and H. K. Peter, personal observations).

The rise of the water temperature in Lake Victoria also resulted in higher stability of the water column (Hecky, 1993; Cózar et al., 2012) and may also have affected Nile perch distribution. For instance, Getabu et al. (2003) observed high Nile perch densities in warmer, shallow waters. However, other studies observed a negative or no relationship between Nile perch densities and water temperature (Goudswaard et al., 2011; Nyboer \& Chapman, 2013; TaabuMunyaho et al., 2013).

In addition to abiotic environmental variables, prey abundance can affect Nile perch distribution and population size structure as well as their diets. A decline in prey abundance can decrease the condition factor of Nile perch (Ogutu-Ohwayo, 1999) and may decrease the size at maturity of fish (Pauly, 1984). A change in prey availability can affect the Nile perch's ontogenetic diet shift from invertebrates to fish and result in profound changes in mean population size and maximum size of Nile perch through changing growth and mortality rates (Downing et al., 2013). There are indications that Nile perch moves to habitats where its preferred prey is abundant. Goudswaard et al. (2011), for instance found that Nile perch stayed near the bottom in deep water where Caridina densities are high when oxygen conditions are favorable. He suggested that the distribution of Caridina may explain the distribution of Nile perch during the time when haplochromine populations were declining. 
Most studies on the Nile perch stock in Lake Victoria focussed on whole lake dynamics over long periods and on the impacts of the Nile perch fisheries (Mkumbo, 2002; Getabu et al., 2003; Mkumbo et al., 2007). In addition, Nile perch distribution was generally studied in open waters of more than $15 \mathrm{~m}$ depth where most of the commercial Nile perch fishery is concentrated (Mkumbo, 2002; Getabu et al., 2003). Little is known about how changes in abiotic factors as for instance caused by eutrophication or climate change will affect the Nile perch stock and at what scales such effects will become apparent. Therefore, there is a need to identify the environmental drivers of Nile perch densities and to identify the spatial and temporal scales at which such drivers are relevant.

We studied how Nile perch is distributed over a range of spatial and seasonal scales and related this to abiotic and biotic environmental variables. Three large regions in south-east Lake Victoria were selected: the Mwanza Gulf, the Speke Gulf and the waters near Kome Island (Sengerema district). In addition, we studied Nile perch distributions on a local, more detailed scale within the Mwanza Gulf. We tested the following hypotheses: (i) Nile perch distribution is regulated by the same environmental factors on both the regional and the local scale; (ii) Driving factors act differently on different Nile perch size classes.

\section{Materials and methods}

Study area

Data were collected in south-east Lake Victoria at 14 sampling stations in the Mwanza Gulf, the Speke Gulf and near Kome Island in the Sengerema district, from here on referred to as Sengerema, (Fig. 1) from September 2009 to April 2011. The three regions differ in habitat: Mwanza Gulf has a strong coastal and littoral influence as the Gulf is narrow and shallow. Speke Gulf is wider and deeper and the stations sampled in Sengerema are deep and located in open water. Sampling stations were at least $8 \mathrm{~km}$ apart and at least $1.5 \mathrm{~km}$ from the shore. Maximum depth, water temperature, and water quality parameters varied between stations during the study period (Table 1). The bottom at all stations mainly consisted of soft mud with occasional rocks at the Speke and Sengerema stations.
Mwanza Gulf, Speke Gulf and the waters in Sengerema are all commercially fished for Nile perch. The southern part of Mwanza Gulf, south of station 3, is officially closed for fishing from January to June, but this is not enforced and Nile perch is fished all year round. Here, Nile perch are fished on a relatively small scale and sold on local markets, whereas Nile perch caught in the open waters near the entrance of the Gulf, in Speke Gulf and in Sengerema generally are targeted for the international export market of frozen fillets (M. Medard, personal communication).

\section{Climate}

Seasons in Lake Victoria are based on the yearly monsoon cycles. In southern Lake Victoria, a dry season from June to August is characterized by strong southerly winds with minimal precipitation, low temperatures, and a well-mixed, oxygenated water column (Talling, 1966; Akiyama et al., 1977). From September to December, a transition to calm weather occurs with stratification gradually building up and precipitation increasing. From January to May precipitation and temperature are highest. Stratification is strongest from January to March (Talling, 1966), resulting in hypoxia near the bottom in waters of $>40$ m depth (Hecky, 1994).

\section{Data collection}

Fish, prey organisms, water temperature, and water quality variables were all sampled within 10 days intervals at each station. Mwanza stations 1-6 were sampled 10-16 times from September 2009 until April 2011, stations 7 and 8 were sampled 6-7 times from June 2009 until April 2011. Stations 9-14 in Speke Gulf and in Sengerema were sampled 2-4 times between June 2009 and May 2010 (Table 2). Data from 2009 to 2011 were used for analyses on a regional scale between Mwanza Gulf, Speke Gulf and Sengerema, whereas data from 2010 to 2011 were used for analyses within Mwanza Gulf.

Nile perch $>5 \mathrm{~cm}$ standard length were collected using multifilament gillnet fleets consisting of panels with stretched mesh sizes ranging from 1 to $8 \mathrm{in}$. (25-203 mm) with increments of 0.5 in. $(13 \mathrm{~mm})$ for panels of 1-6 in. and with increments of 1 in. $(25 \mathrm{~mm})$ for panels of 6-8 in. (152-203 mm). Panels varied in surface area, from $58 \mathrm{~m}^{2}$ for a panel of $1 \mathrm{in}$. mesh size 


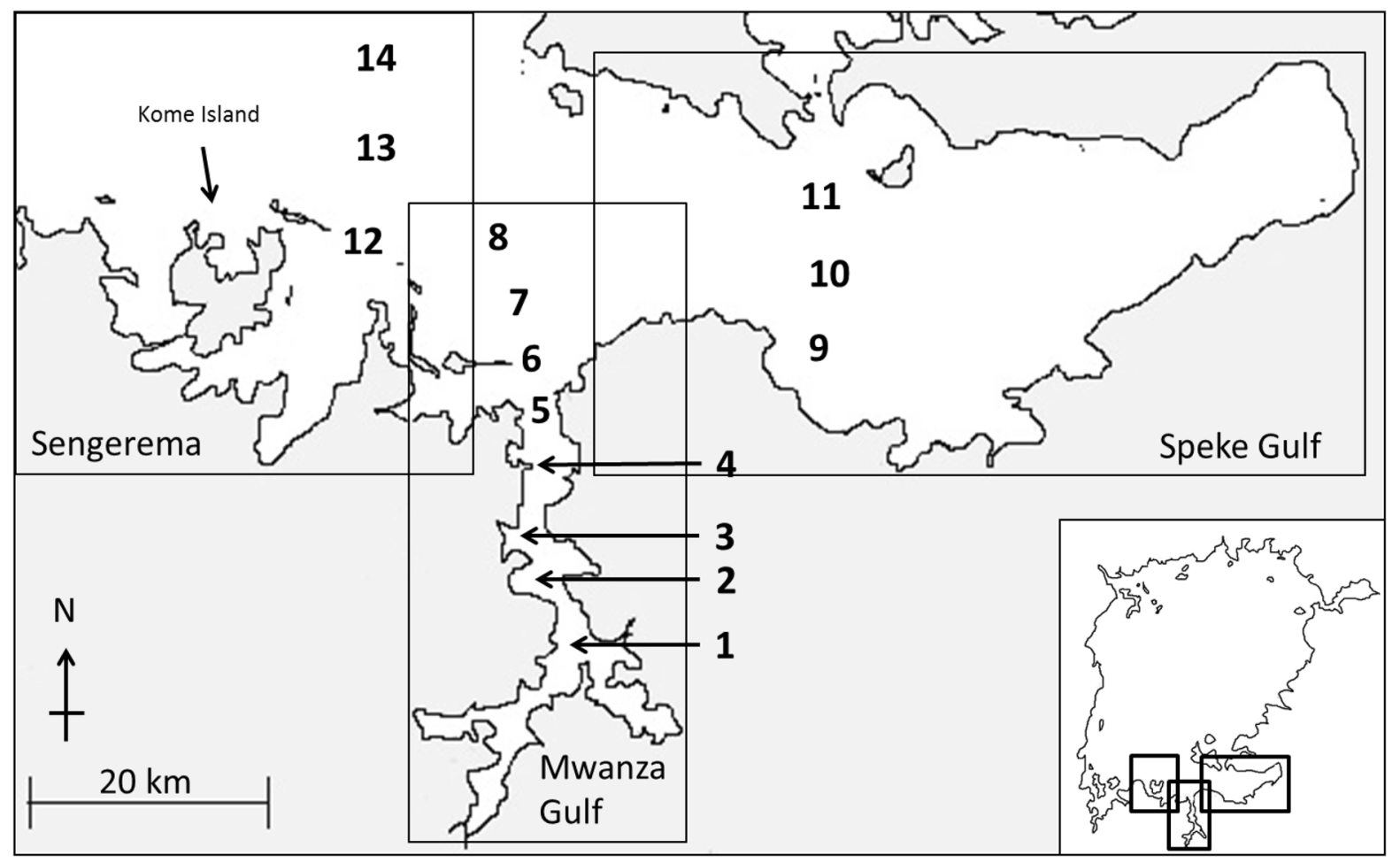

Fig. 1 Map of south-east Lake Victoria with stations in the three regions: Mwanza Gulf (1-8) with a depth range of 5-44 m from station 1-8, Speke Gulf (9-11) with a depth range of
17-34 m from station 9-11, and Sengerema (near Kome Island) (12-14) with a depth range of 41-55 $\mathrm{m}$ from station 12-14

as: odonate/ephemeropteran nymph, mollusc, Caridina nilotica shrimp, Rastrineobola argentea (Pellegrin) (a small cyprinid fish), haplochromine cichlids, Nile perch, other fish species, and unidentified fish remains.

A hydrolab DS5 multiprobe (OTT Messtechnik $\mathrm{GmbH} \& \mathrm{Co}$, Kempten, Germany) collected vertical profiles of temperature and oxygen concentrations from the lake bottom to the surface during the day. Oxygen concentration was calibrated using the Winkler method (American Public Health Association, 2005). Secchi depth was measured in triplicate with a $25 \mathrm{~cm}$ diameter black and white Secchi disk and was defined as the mean depth at which the disk disappeared when lowering it in the water and re-appeared when lifting it.

Observations on the distribution of Caridina in the Mwanza Gulf were carried out in triplicate per station by hauling a $1 \mathrm{~m}^{2}$ square lift net from bottom to surface. Samples were preserved in 5\% formaldehyde solution and numbers were counted in the laboratory. 
Table 1 Maximum depths, average water temperature, and means of water quality parameters measured at the sampling stations during the study period

\begin{tabular}{|c|c|c|c|c|c|c|}
\hline Region & Station & $N$ & $\begin{array}{l}\text { Maximum depth } \\
\left(D_{\max }, \text { in } \mathrm{m}\right)\end{array}$ & $\begin{array}{l}\text { Temperature of } \\
\text { the water column }\left(T \text {, in }{ }^{\circ} \mathrm{C}\right)\end{array}$ & $\begin{array}{l}\text { Dissolved oxygen } \\
\left(\mathrm{DO}, \text { in } \mathrm{mg}^{-1}\right)\end{array}$ & $\begin{array}{l}\text { Visibility } \\
(\mathrm{Sd}, \text { in } \mathrm{m})\end{array}$ \\
\hline \multirow[t]{8}{*}{ Mwanza } & 1 & 9 & 5 & 24.5 & 7.1 & 0.63 \\
\hline & 2 & 9 & 7 & 25.1 & 7.4 & 0.67 \\
\hline & 3 & 9 & 8 & 24.8 & 6.8 & 1.02 \\
\hline & 4 & 10 & 11 & 25.2 & 7 & 1.20 \\
\hline & 5 & 9 & 18 & 24.9 & 6.1 & 1.73 \\
\hline & 6 & 14 & 28 & 25.3 & 5.3 & 1.99 \\
\hline & 7 & 7 & 39 & 24.7 & 5.6 & 1.90 \\
\hline & 8 & 6 & 44 & 24.6 & 5.5 & 2.20 \\
\hline \multirow[t]{3}{*}{ Speke } & 9 & 3 & 17 & 25 & 4.5 & 2.00 \\
\hline & 10 & 3 & 29 & 24.6 & 4.9 & 2.00 \\
\hline & 11 & 3 & 34 & 24.9 & 5.8 & 2.30 \\
\hline \multirow[t]{3}{*}{ Sengerema } & 12 & 2 & 41 & 25 & 5.1 & 1.30 \\
\hline & 13 & 3 & 50 & 24.9 & 5 & 1.40 \\
\hline & 14 & 4 & 55 & 25.1 & 6.4 & 1.80 \\
\hline
\end{tabular}

Temperature and dissolved oxygen are means calculated over the whole water column. $N$ number of observations. For position of sampling stations see Fig. 1

Table 2 Sampling frequency and fleet settings at stations during the study period

\begin{tabular}{|c|c|c|c|c|c|c|c|c|c|c|}
\hline \multirow[t]{2}{*}{ Region } & \multirow[t]{2}{*}{ Station } & \multirow[t]{2}{*}{$D_{\max }(\mathrm{m})$} & \multirow[t]{2}{*}{ Fleet setting } & \multicolumn{2}{|l|}{2009} & \multicolumn{4}{|l|}{2010} & \multirow{2}{*}{$\begin{array}{l}2011 \\
\text { Jan-Mar }\end{array}$} \\
\hline & & & & Jun-Sept & Oct-Dec & Jan-Mar & Apr-May & Jun-Sept & Oct-Dec & \\
\hline \multirow[t]{8}{*}{ Mwanza } & 1 & 5 & $\mathrm{~S}$ & - & 2 & - & - & 4 & 3 & 2 \\
\hline & 2 & 7 & $\mathrm{~S}$ & - & 3 & - & 3 & 4 & 3 & 3 \\
\hline & 3 & 8 & $\mathrm{~S}$ & - & 3 & - & - & 4 & 3 & 3 \\
\hline & 4 & 11 & S, B & - & 2 & - & 3 & 4 & 1 & - \\
\hline & 5 & 18 & S, M, B & - & 2 & - & - & 3 & 3 & 2 \\
\hline & 6 & 28 & $\mathrm{~S}, \mathrm{M}, \mathrm{B}$ & 1 & 2 & - & 4 & - & 3 & 5 \\
\hline & 7 & 39 & $\mathrm{~S}, \mathrm{M}, \mathrm{B}$ & 1 & - & - & 2 & 1 & - & 3 \\
\hline & 8 & 44 & $\mathrm{~S}, \mathrm{M}, \mathrm{B}$ & 1 & - & - & 2 & 1 & - & 2 \\
\hline \multirow[t]{3}{*}{ Speke } & 9 & 17 & $\mathrm{~S}, \mathrm{M}, \mathrm{B}$ & 1 & - & 1 & 1 & - & - & - \\
\hline & 10 & 29 & $\mathrm{~S}, \mathrm{M}, \mathrm{B}$ & 2 & - & 1 & - & - & - & - \\
\hline & 11 & 34 & $\mathrm{~S}, \mathrm{M}, \mathrm{B}$ & 2 & - & 1 & - & - & - & - \\
\hline \multirow[t]{3}{*}{ Sengerema } & 12 & 41 & $\mathrm{~S}, \mathrm{M}, \mathrm{B}$ & - & - & 2 & - & - & - & - \\
\hline & 13 & 50 & $\mathrm{~S}, \mathrm{M}, \mathrm{B}$ & 1 & - & 2 & - & - & - & - \\
\hline & 14 & 55 & S, M, B & 2 & - & 2 & - & - & - & - \\
\hline
\end{tabular}

$D_{\max }$ maximum depth (m); gillnet fleet set at $S$ the surface; $B$ the bottom; and $M$ the middle of the water column. For position of sampling stations see Fig. 1

Data analysis

\section{Spatial and temporal distribution differences}

CPUE was calculated in numbers per standardized fleet per hour (no. setting ${ }^{-1}$ ). A standardized fleet was calculated as the mean surface area of one fleet $\left(\mathrm{m}^{2}\right)$. To enable comparisons between stations with different proportion of gillnet coverage of the water column, we estimated catch per unit effort (CPUE, no. setting ${ }^{-1}$ ) over the whole water column, by interpolation for the part of the water column not covered by gillnets at 


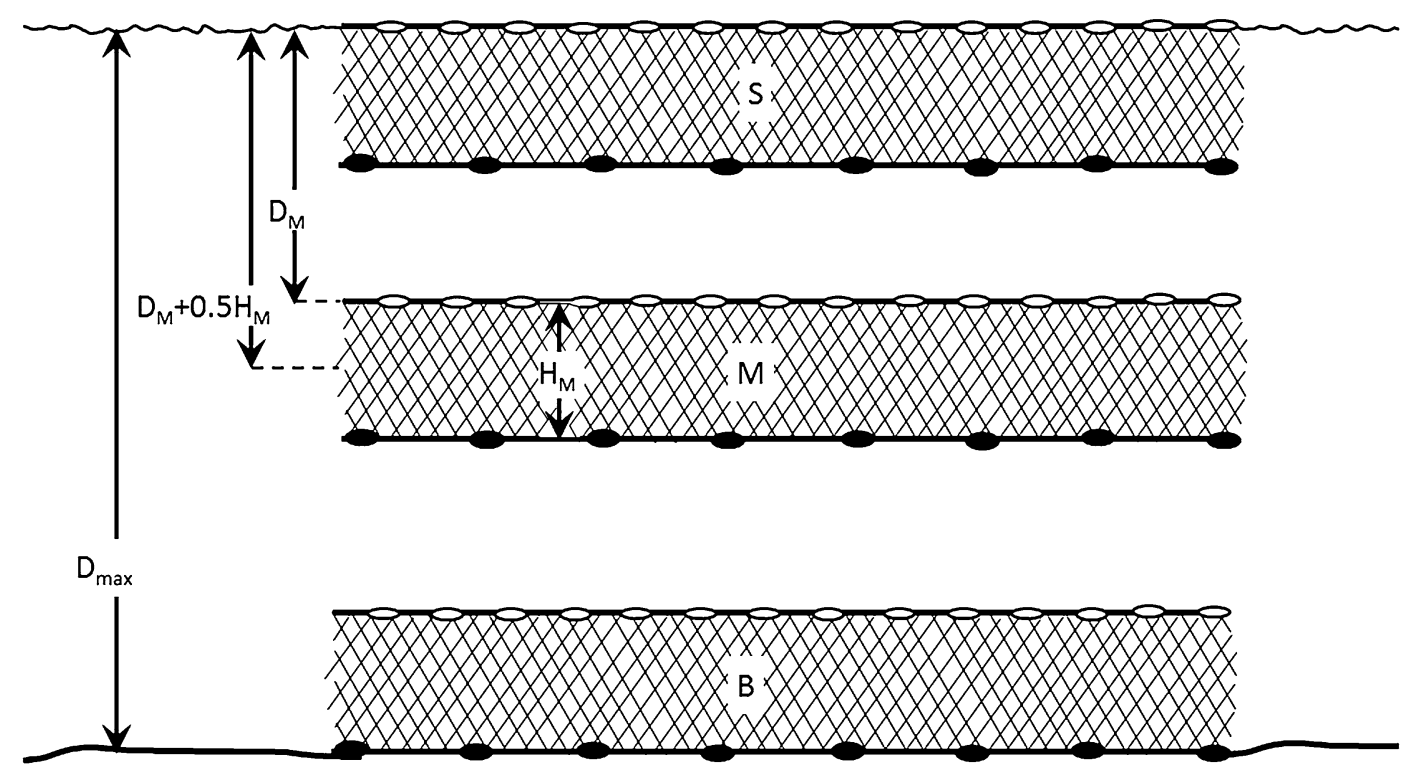

Fig. 2 A schematic representation of the gillnet fleet sets. In deep stations fleets were positioned at the water surface $(S)$, in the middle $(M)$ of the water column at depth $D_{\mathrm{M}}$ and at the bottom $(B)$. $H_{\mathrm{M}}$ height of the nets of the middle fleet; $D_{\max }$ depth of the water column

stations deeper than $15 \mathrm{~m}$. The mean value of the CPUE of the surface and middle panels was used to calculate the CPUE of the top part of the water column. This value was weighted for the depth of this part of the water column. Similarly, the mean value of the CPUE of the bottom part of the water column was calculated as the mean value of the middle and bottom fleet, weighted for the depth of this part of the water column. Total CPUE was the sum of the CPUE values of the top and bottom parts of the water column:

$$
\begin{aligned}
& \mathrm{CPUE}=\frac{\mathrm{CPUE}_{\mathrm{S}}+\mathrm{CPUE}_{\mathrm{M}}}{2} \times \frac{D_{\mathrm{M}}+0.5 \times H_{\mathrm{M}}}{D_{\max }}+ \\
& \frac{\mathrm{CPUE}_{\mathrm{M}}+\mathrm{CPUE}_{\mathrm{B}}}{2} \times \frac{D_{\max }-\left(D_{\mathrm{M}}+0.5 \times H_{\mathrm{M}}\right)}{D_{\max }},
\end{aligned}
$$

where $\mathrm{CPUE}_{\mathrm{S}}, \mathrm{CPUE}_{\mathrm{M}}$, and $\mathrm{CPUE}_{\mathrm{B}}$ are the CPUE values for the surface, middle, and bottom fleet, respectively, $H_{\mathrm{M}}$ is the height of the middle fleet, and $D_{\max }$ is the depth of the water column (Fig. 2).

Spatial effects on Nile perch size class distributions on a regional scale between Mwanza Gulf, Speke Gulf, and Sengerema were analyzed by Kruskal-Wallis tests, because normality of the residuals could not be achieved directly, or after transformation. Spatial and temporal effects on Nile perch size class distributions in the Mwanza Gulf were also analysed by Kruskal-Wallis tests. In case of significant spatial or temporal effects, post hoc pairwise comparisons were performed with adjusted levels for multiple comparisons using a Bonferroni correction ( $\mathrm{df}=5, P=0.003$ for spatial comparisons within the Mwanza Gulf and $\mathrm{df}=4$, $P=0.005$ for temporal comparisons within the Mwanza Gulf and spatial comparisons on a regional scale).

Data of the residuals of prey densities of Caridina and haplochromines were non- normally distributed and spatial effects were tested with Kruskal-Wallis tests and post hoc pairwise comparisons were corrected according to Bonferroni ( $\mathrm{df}=5, P=0.003$ for spatial comparisons within the Mwanza Gulf and df $=4, P=0.005$ for spatial comparisons on a regional scale). Caridina densities were only sampled in the Mwanza Gulf stations 1-6.

\section{Multivariate analyses}

We investigated variability in Nile perch distributions in relation to environmental factors using multivariate analyses. Detrended correspondence analyses (DCA) on log-transformed data were used to determine the length of the environmental gradient, to choose the appropriate response model. For all analyses, the gradient length suggested that the response models could be either linear or unimodal. Subsequently we chose to use linear redundancy analyses (RDA) to explain Nile perch size class distributions by environmental variables on a local scale within the Mwanza 
Gulf and on a regional scale between Mwanza Gulf, Speke Gulf, and Sengerema. Year was used as a covariable. All multivariate analyses were carried out with CANOCO 4.55 (Biometris, Plant Research International, Wageningen, The Netherlands).

\section{Generalized additive model (GAM) analyses}

We used GAMs to investigate the relationships between Nile perch size class distribution and maximum depth, temperature, oxygen concentration, Secchi depth, and haplochromine and Caridina densities using the same data set as for the DCA. GAM is a nonparametric regression technique to model non-linear relationships and can be used with non-normally distributed data. We used the densities of Nile perch and haplochromines (CPUE in numbers per standardized fleet) for bottom, middle or surface sets in the water column. Means of temperature and oxygen were calculated over the depth at which a fleet of gillnets was set. Although densities of some Nile perch size classes were not normally distributed after log-transformations and some fitted a gamma distribution, GAM models fitted best with log-transformed Nile perch densities with a Gaussian error distribution and identity link function. Generalized cross validation (GCV) was used to choose the optimal degree of smoothing for each variable. We started with a model including all environmental variables as smooth, non-linear terms. When the degrees-of-freedom, estimated by GCV, of a variable was one, it was considered as a linear regression. Non-significant terms were excluded from the model. The model predicted densities of Nile perch for each smoothing and/or linear component (partial prediction). The partial prediction is the portion of the predicted response of Nile perch densities that is attributed to an environmental variable. Partial predictions were plotted against environmental variables to explore the nature of the relationships between Nile perch densities and environmental drivers. GAM analyses were carried out in R 3.1.0 (R Foundation for Statistical Computing, Vienna, Austria).

\section{Logistic regression analyses}

Nile perch diets were weighted for the fullness of stomachs to calculate the frequency of occurrence of prey. The diet category 'fish' consisted of haplochromines and unidentified fish remains. On average, $47 \%$ of the Nile perch stomachs were empty. Empty stomachs were excluded from further data analyses. To test the frequency of occurrence of prey in the diet as a function of Nile perch size classes, we used binomial logistic regression models with absence/presence of prey in the stomach. Binomial logistic regressions were then tested using Wald tests. Non-parametric and logistic regression analyses were carried out in SAS 9.2 (SAS Institute, Cary, USA).

\section{Results}

Spatial and temporal distributions of Nile perch

\section{Local scale}

When comparing the CPUE over the whole water column on a local scale within the Mwanza Gulf, Nile perch size classes between 10 and $40 \mathrm{~cm}$ varied spatially with significantly higher densities at shallow stations 1-3 than in deeper water at 4-6 (Fig. 3). Small Nile perch of $5-10 \mathrm{~cm}$ varied seasonally with highest densities from November to February during the wet seasons and lowest densities from July to August during the dry season (Fig. 3).

\section{Regional scale}

On a regional scale, CPUE over the whole water column of Nile perch size classes between 5 and $40 \mathrm{~cm}$ was highest at the shallowest station of Mwanza (Mw1) and lowest in Sengerema (Fig. 3). Small-sized Nile perch of size classes between 5 and $20 \mathrm{~cm}$ were especially abundant in the Mwanza Gulf. Densities of Nile perch of $20-40 \mathrm{~cm}$ were similar between the medium and deep stations of Mwanza (Mw2, 3) and Speke Gulf. Densities of Nile perch of $>40 \mathrm{~cm}$ were lowest at the medium stations of the Mwanza Gulf (Mw2) and similar in the other regions (Fig. 3).

Factors determining Nile perch distributions

Local scale

On a local scale within the Mwanza Gulf, detrended correspondence analysis (DCA) showed a gradient length of the first ordination axis of 2.3 , indicating either a linear or a unimodal relationship between the 


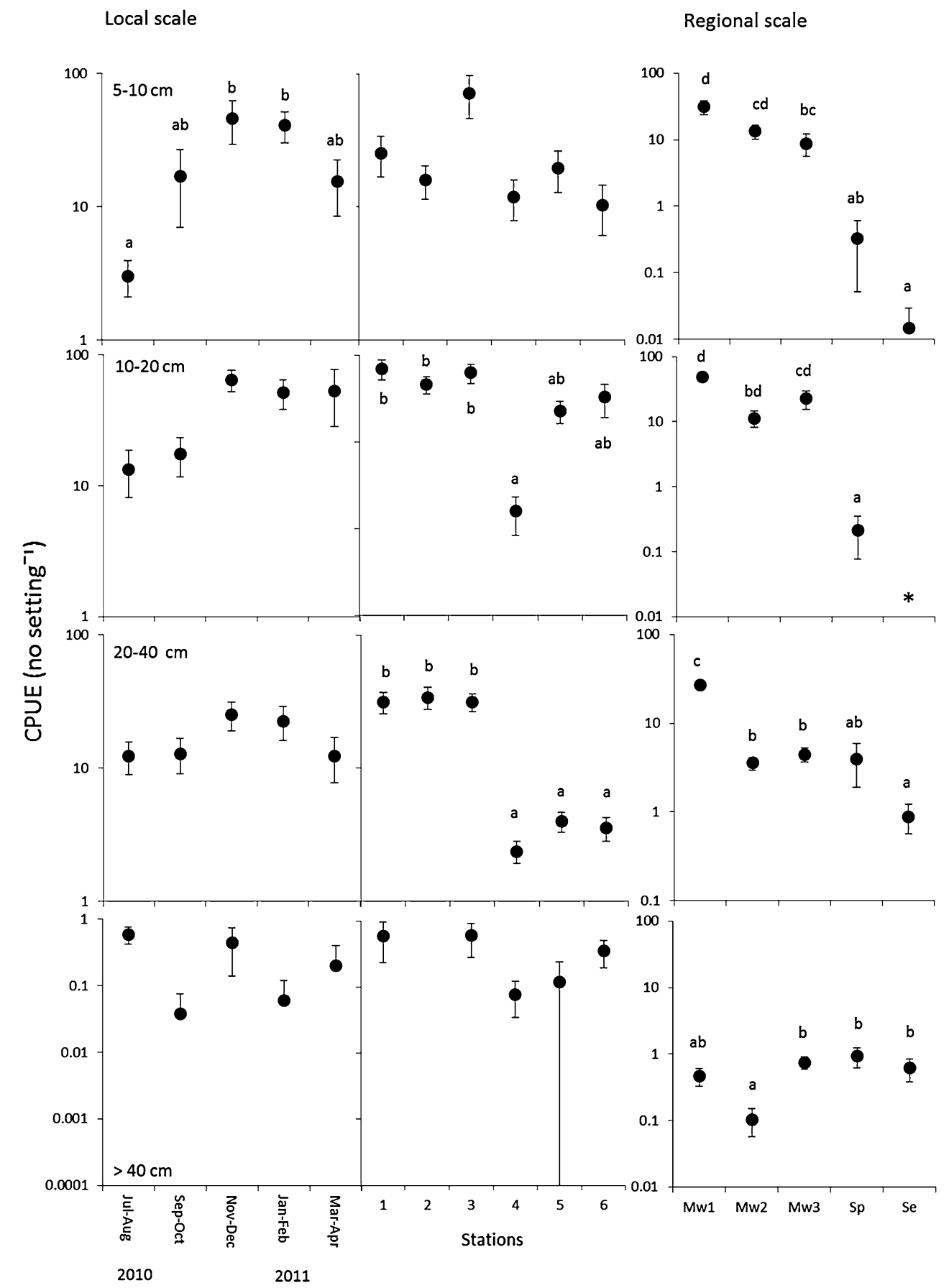

Fig. 3 Mean Nile perch densities (CPUE of the whole water column) and standard errors of different size classes on a local scale in the Mwanza Gulf from 2010 to 2011 and on a regional scale in the Mwanza Gulf, Speke Gulf and in Sengerema from 2009 to 2011. Nile perch size classes were: 5-10, 10-20, 20-40, and >40 cm. For local scale 1-6 Mwanza Gulf stations 1-6; and for regional scale: Mw1 Mwanza stations 1-3, Mw2 Mwanza stations 4-5, Mw3 Mwanza stations 6-8, Sp Speke stations 9-11 and Se Sengerema stations 12-14. For position of stations see Fig. 1. Identical letters above the means in the figure indicate non-significant differences between catches in a multiple comparison test $(P \geq 0.05)$ 
environmental gradient and Nile perch distributions. We chose a linear redundancy analysis (RDA) to relate Nile perch size class distributions to abiotic and biotic environmental factors (Fig. 4). The RDA ordination was significant for all axes $(F=4.79, P=0.001$, Monte Carlo test, 1000 replicates) with the first two axes explaining $22.3 \%$ of the variation. Generalized additive models (GAM) of Nile perch size class distributions and environmental factors showed both significant linear and non-linear regressions (Table 3; Fig. 5).

There was a strong spatial pattern in the RDA ordination, with a clear gradient between stations 1-6, correlating strongly with the maximum depth of the water column (Figs. 4a, c). The seasonal pattern was less conspicuous, with July-August (dry season) being most distinct from the rest of the year (Fig. 4e). This pattern was strongly correlated with low temperatures in the dry season. Densities of Nile perch of $20-40 \mathrm{~cm}$ were related to shallow stations of the Mwanza Gulf (Figs. 4a, c). GAM analyses showed that densities of Nile perch size classes of 5-10, 20-40 and $>40 \mathrm{~cm}$ decreased with depth linearly and non-linearly, respectively (Table 3; Fig. 5). Partial predictions of densities of Nile perch of 10-20 cm versus maximum depth showed a quadratic-shaped pattern with minimum predicted densities at 10-20 m depth (Fig. 5).

Visibility (Secchi depth) was closely correlated to maximum depth, although the influence of the former on the ordination was less strong (Figs. 4a, c). GAM analyses showed that visibility was negatively related to Nile perch size classes between 10 and $40 \mathrm{~cm}$ and positively, linearly related to Nile perch $>40 \mathrm{~cm}$ (Table 3; Fig. 5).

Oxygen concentration was influenced more or less equally by space and season with higher concentrations in shallow waters and in July-October (Figs. 4a, c, e). GAM analyses did not show any relationships between the observed oxygen concentrations and Nile perch densities (Table 3).

Temperature was positively related to the density of small Nile perch size classes between 5 and $20 \mathrm{~cm}$ (Fig. 4a). This was confirmed by the GAM analyses, showing a non-linear increase with maximum predicted densities at $24-25^{\circ} \mathrm{C}$ (Table 3; Fig. 5).

Caridina densities were of minimal influence on the RDA ordination of Nile perch distributions in the Mwanza Gulf. (Figure 3a). GAM analyses showed that Caridina densities were negatively and linearly related to densities of Nile perch 10-20 cm (Table 3; Fig. 5). Caridina densities increased with depth and were highest at station 6 and lowest at station 1 (Fig. 6a). The contribution of Caridina in the Nile perch diet was significantly related to the size of Nile perch (Fig. 6d, $P<0.05$, Wald test). The largest contribution of Caridina in the diet was found in Nile perch size classes between 5 and $20 \mathrm{~cm}$ and at stations 5 and 6. At station 1, the contribution of Caridina in the diet was low for all size classes.

Haplochromine densities also had a minimal influence on the RDA ordination (Fig. 3a). GAM analyses showed that Nile perch of $20-40 \mathrm{~cm}$ was related with an sinus-shaped pattern showing a local minimum at a density of ca. 10-15 haplochromines per standardized setting after which Nile perch densities increase with haplochromine densities (Table 3; Fig. 5). Between stations in the Mwanza Gulf, no significant differences in haplochromine densities were found (Fig. 6b). The contribution of fish in the Nile perch diet was significantly related to Nile perch length at all stations (Fig. 6f, $P<0.05$, Wald test). The largest contribution of fish in the diet was found in Nile perch size classes of $>20 \mathrm{~cm}$, except for shallow waters in the Mwanza Gulf where Nile perches of all size classes predominantly fed on fish (Fig. 6f).

\section{Regional scale}

On a regional scale, detrended correspondence analyses (DCA) resulted in a gradient length of the first ordination axis of 3.6, which indicates either a linear or a unimodal relationship between the environmental gradient and Nile perch distributions. We chose linear redundancy analyses (RDA) to relate Nile perch size class distributions to environmental factors. The RDA ordination was significant for all axes $(F=21.72, P=0.001$, Monte Carlo test, 1000 replicates). The first two axes explained $31.8 \%$. Generalized additive models (GAM) showed both significant linear and non-linear regressions between Nile perch densities and environmental factors (Table 3; Fig. 5).

Of all environmental factors, maximum depth influenced the RDA ordination most, primarily differentiating the shallower stations of Mwanza Gulf (Mw1, Mw2) from the deeper stations (Mw3) and Speke Gulf and Sengerema (Figs. 4b, d). Maximum 
Local scale
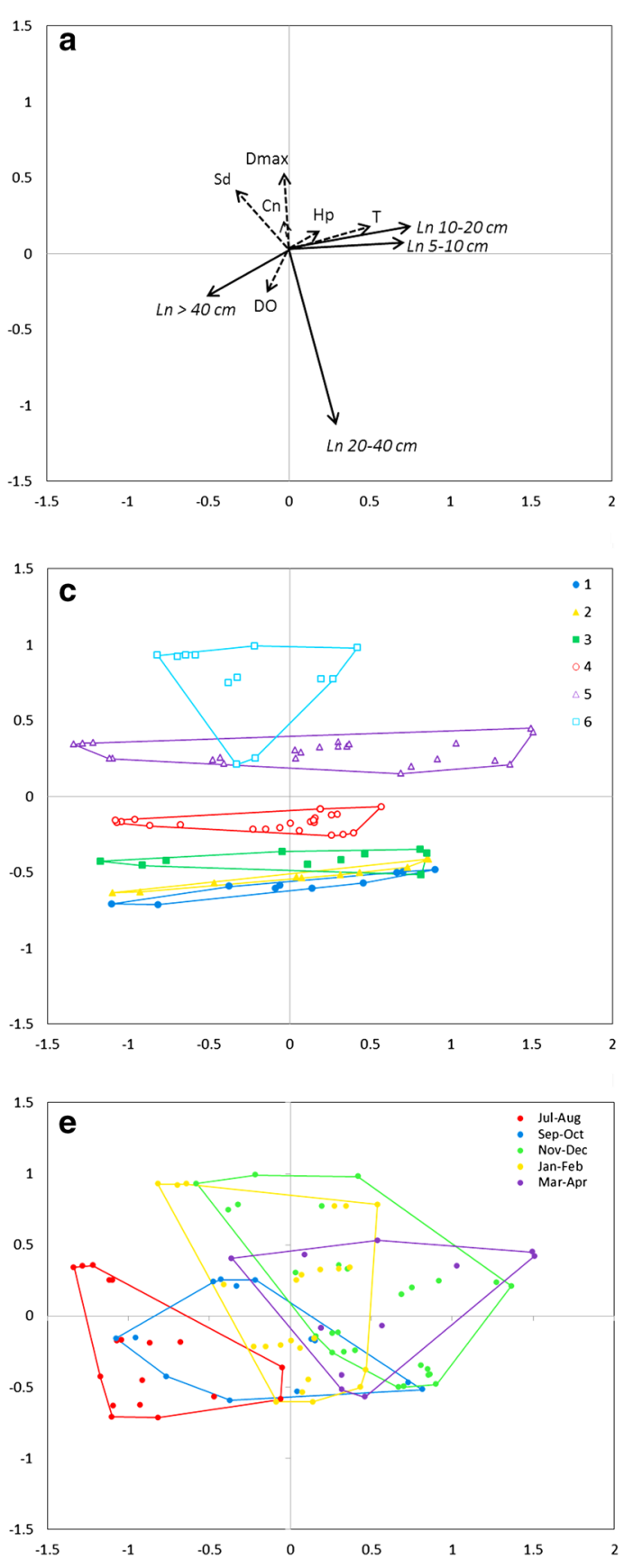

Regional scale
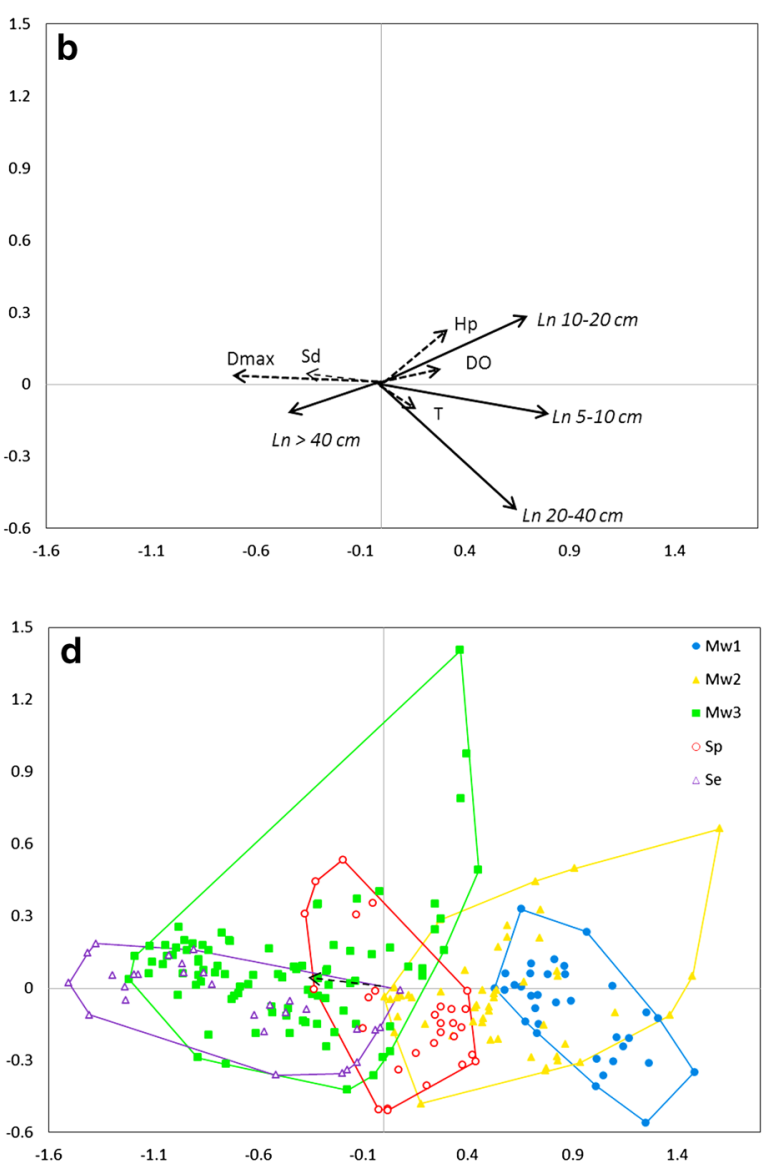

Fig. 4 Spatial and seasonal distribution of Nile perch densities in relation to environmental factors on a local spatial scale within the Mwanza Gulf and on a regional spatial scale in the Mwanza Gulf, Speke Gulf and in Sengerema. a-b RDA biplot of densities of Nile perch size classes in relation to environmental factors temperature $(T)$, dissolved oxygen (DO), maximum depth $\left(D_{\max }\right)$, Secchi depth $(\mathrm{Sd})$, Caridina densities $(\mathrm{Cn})$, and haplochromine densities $(\mathrm{Hp})$. Abbreviations used for Nile perch size classes: Ln 5-10 cm, Ln 10-20 cm, Ln 20-40 cm, and Ln > $40 \mathrm{~cm}$. c-d RDA scatter plot of spatial distribution of Nile perch densities. Abbreviations used for indicating Mwanza Gulf stations and regions see caption Fig. 3. For position of stations see Fig. 1; and e RDA scatter plot of seasonal distribution of Nile perch densities in the Mwanza Gulf 
depth was negatively related to Nile perch size classes between 5 and $40 \mathrm{~cm}$ (Fig. 4b). This was confirmed by GAM analyses, showing a non-linear decrease of densities of Nile perch size classes between 5 and $40 \mathrm{~cm}$ with depth (Table 3, Fig. 5). Densities of Nile perch $>40 \mathrm{~cm}$ linearly increased with depth (Table 3 ; Fig. 5).

Visibility (Secchi depth) was positively correlated to maximum depth, although its influence on the RDA ordination was less strong (Fig. 4b). GAM analyses showed an increase of densities of Nile perch of 10-20 and $>40 \mathrm{~cm}$ with visibility, of which Nile perch $>40 \mathrm{~cm}$ showed a sine-shaped function with increasing densities from $2 \mathrm{~m}$ visibility and up (Table 3; Fig. 5). Nile perch of 5-10 cm showed an irregular pattern with visibility (Fig. 5).

Oxygen concentrations were negatively correlated with depth, with the highest concentrations in the shallow waters of Mwanza Gulf (Figs. 4b, d). Oxygen concentration was positively related to the density of small Nile perch size classes between 5 and $20 \mathrm{~cm}$ and negatively with Nile perch $>40 \mathrm{~cm}$ in the RDA (Fig. 4b). GAM analyses confirmed a positive non-linear relationship between oxygen concentrations and densities of Nile perch size classes between 5 and $20 \mathrm{~cm}$ (Table 3; Fig. 5). Partial predictions showed an increase of Nile perch densities above an oxygen concentration of $8 \mathrm{mg}^{-1}$ (Fig. 5). In contrast, Nile perch $20-40 \mathrm{~cm}$ showed a negative linear relationship with oxygen concentration (Table 3; Fig. 5).

Temperature was positively related to the density of Nile perch size classes between 5 and $40 \mathrm{~cm}$ in the RDA and negatively to density of Nile perch $>40 \mathrm{~cm}$ (Fig. 4b). GAM analyses showed that temperature affected all Nile perch size classes (Table 3). Densities of Nile perch size classes between 5 and $20 \mathrm{~cm}$ showed positive non-linear relationships with maximum predicted densities at $24-26^{\circ} \mathrm{C}$ (Fig. 5). Densities of Nile perch of $20-40 \mathrm{~cm}$ showed a positive linear relationship with temperature and Nile perch $>40 \mathrm{~cm}$ showed minimum densities at a temperature of $25^{\circ} \mathrm{C}$ (Fig. 5).

The inclusion of Caridina in the diet was negatively related to Nile perch length in all regions $(P<0.006$, Wald test), except in Sengerema $(P=0.19)$ (Fig. 6e). Nile perch of size classes between 5 and $20 \mathrm{~cm}$ fed predominantly on Caridina, except in shallow waters of the Mwanza Gulf (Fig. 6e: Mw1) where they had a larger proportion of fish in their diets.

Table 3 General additive models (GAM) of non-parametric regressions between Nile perch densities and environmental variables on a local and regional scale

\begin{tabular}{|c|c|c|c|c|c|c|c|c|c|c|c|c|}
\hline & \multicolumn{3}{|c|}{ Nile perch $5-10$} & \multicolumn{3}{|c|}{ Nile perch $10-20$} & \multicolumn{3}{|c|}{ Nile perch $20-40$} & \multicolumn{3}{|c|}{ Nile perch $>40$} \\
\hline & Statistics & $P$ & df & Statistics & $P$ & df & Statistics & $P$ & df & Statistics & $P$ & $\mathrm{df}$ \\
\hline \multicolumn{13}{|l|}{ Local scale } \\
\hline Maximum depth & 4.25 & 0.02 & 2 & 9 & $<0.0001$ & 2 & 3.05 & 0.05 & 2 & 18.80 & $<0.0001$ & 1 \\
\hline Secchi depth & - & n.s. & - & 4.11 & 0.05 & 1 & 3.08 & 0.05 & 2 & 16.13 & 0.0001 & 1 \\
\hline Oxygen & - & n.s. & - & - & n.s. & - & - & n.s. & - & - & n.s & - \\
\hline Temperature & 7.39 & $<0.0001$ & 8 & 4.75 & 0.0004 & 5 & - & n.s. & - & - & n.s & - \\
\hline Caridina & - & n.s. & - & 10.40 & 0.002 & 1 & - & n.s. & - & - & n.s. & - \\
\hline Haplochromines & - & n.s. & - & - & n.s. & - & 3.51 & $<0.006$ & 4 & - & n.s. & - \\
\hline \multicolumn{13}{|l|}{ Regional scale } \\
\hline Maximum depth & 47.39 & $<0.0001$ & 3 & 22.97 & $<0.0001$ & 9 & 15.62 & $<0.0001$ & 7 & 23.95 & $<0.0001$ & 1 \\
\hline Secchi depth & 3.37 & 0.0008 & 8 & 5.95 & $<0.0001$ & 8 & - & - & - & 2.36 & 0.04 & 4 \\
\hline Oxygen & 2.19 & 0.03 & 6 & 5.02 & $<0.0001$ & 7 & 7.82 & 0.004 & 1 & - & - & - \\
\hline Temperature & 8.05 & $<0.0001$ & 6 & 9.91 & $<0.0001$ & 6 & 16.13 & $<0.0001$ & 1 & 3.42 & 0.008 & 3 \\
\hline Caridina & - & - & - & - & - & - & - & - & - & - & - & - \\
\hline Haplochromines & - & n.s. & - & 3.32 & 0.03 & 2 & - & n.s. & - & - & n.s. & - \\
\hline
\end{tabular}

Models for each Nile perch size class included only significant variables. Significant $P$ values are in italics. $F$ test statistics, n.s. not significant term and excluded from model $(P>0.05), d f$ degrees-of-freedom 


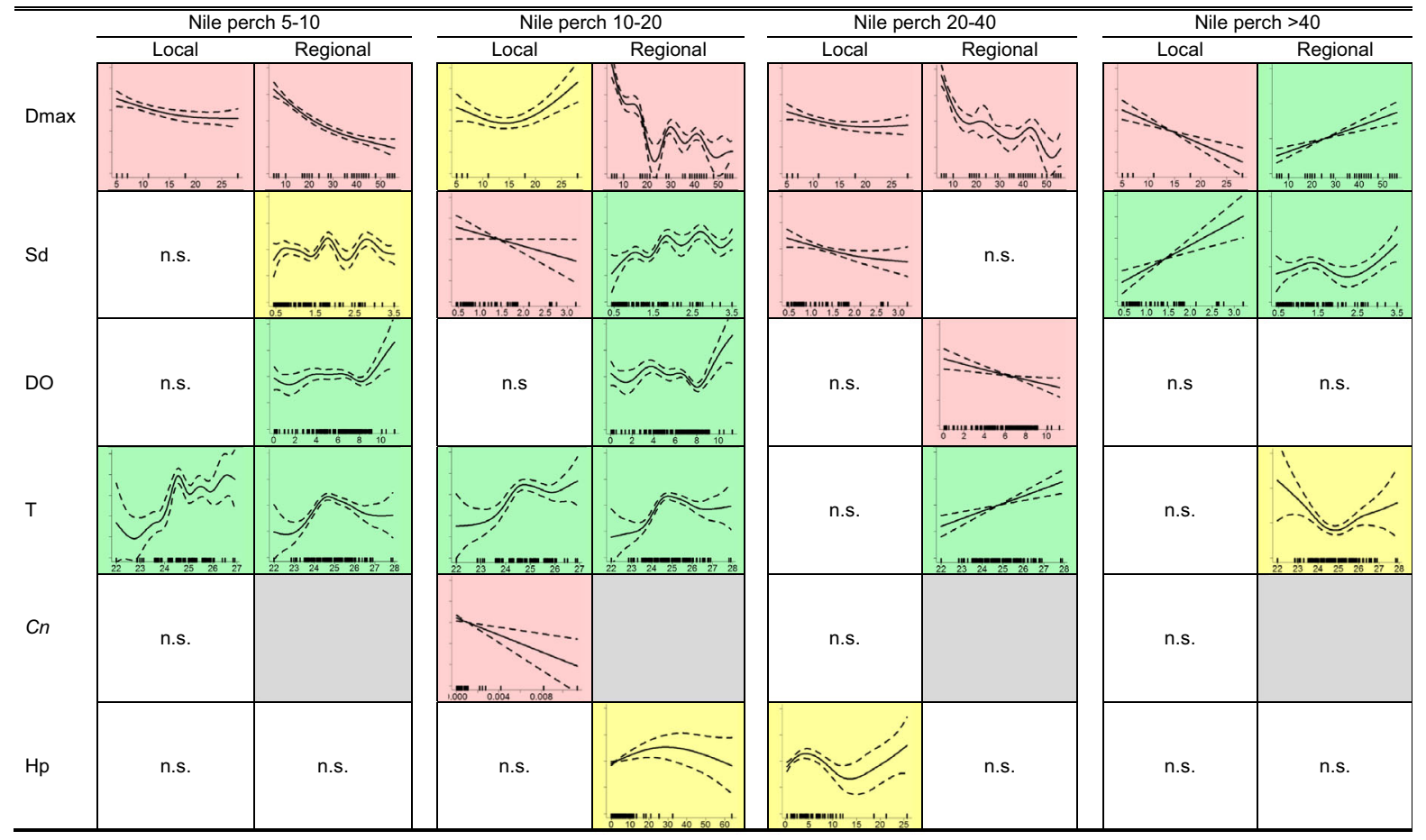

Fig. 5 Regressions of the significant linear and non-linear terms of the GAM models on a local and regional scale. Graphs indicate relationships between environmental variables ( $x$-axis) and partial predictions of Nile perch densities ( $y$-axis). Solid lines indicate the model fit and dashed lines the $95 \%$ confidence intervals. Colors indicate the nature of the relationship; green

Haplochromine densities were highest in the shallow water of the Mwanza Gulf and lowest in the deep water in Sengerema (Fig. 6c). RDA analyses showed that haplochromine densities were positively related to small Nile perch size classes between 5 and $20 \mathrm{~cm}$ and negatively related to large Nile perch of $>40 \mathrm{~cm}$ (Fig. 4b). GAM analyses showed a relationship between haplochromines and Nile perch of 10-20 cm, with increasing Nile perch densities up to 30 haplochromines per setting, after which Nile perch densities decreased with haplochromine densities (Table 3; Fig. 5). The contribution of fish in the diet was positively related to Nile perch length in the Mwanza Gulf and the Speke Gulf $(P<0.006$, Wald test), but not in Sengerema $(P=0.93)$ (Fig. $6 \mathrm{~g})$. The largest contribution of fish in the diet was found in Nile perch size classes of $>20 \mathrm{~cm}$, except for the shallow waters in the Mwanza Gulf where Nile perch of all size classes predominantly fed on fish (Fig. $6 \mathrm{~g}$ ). increase, red decrease and yellow irregular, gray model was not included because of lack of data of Caridina, on a regional scale. n.s. Not significant term and excluded from model; $D_{\max }$ maximum depth (m); Sd Secchi depth (m); DO dissolved oxygen $\left(\mathrm{mg} \mathrm{l}^{-1}\right) ; T$ temperature $\left({ }^{\circ} \mathrm{C}\right)$; $C n$ Caridina density $\left(\right.$ no. $1^{-1}$ ) and $H p$ haplochromine density (no. setting ${ }^{-1}$ )

\section{Discussion}

Spatial and temporal distributions of Nile perch

\section{Local scale}

We found that local scale distributions of Nile perch differed from earlier distributions described in the literature. Highest densities of Nile perch occurred in shallow waters of $<10 \mathrm{~m}$ depth, while in bottom trawl surveys conducted from 1984 to 1990, highest densities were found in the deeper parts of the Gulf ( $>12 \mathrm{~m}$ ) (Goudswaard et al., 2011). Haplochromines were absent in the Gulf by then and Caridina shrimp, occurring in high densities in waters of $>20 \mathrm{~m}$, was the major prey of juvenile Nile perch up to $30 \mathrm{~cm}$ (Katunzi et al., 2006).

The high densities of haplochromines in the Mwanza Gulf observed in our study confirm their 
Local scale

Regional scale
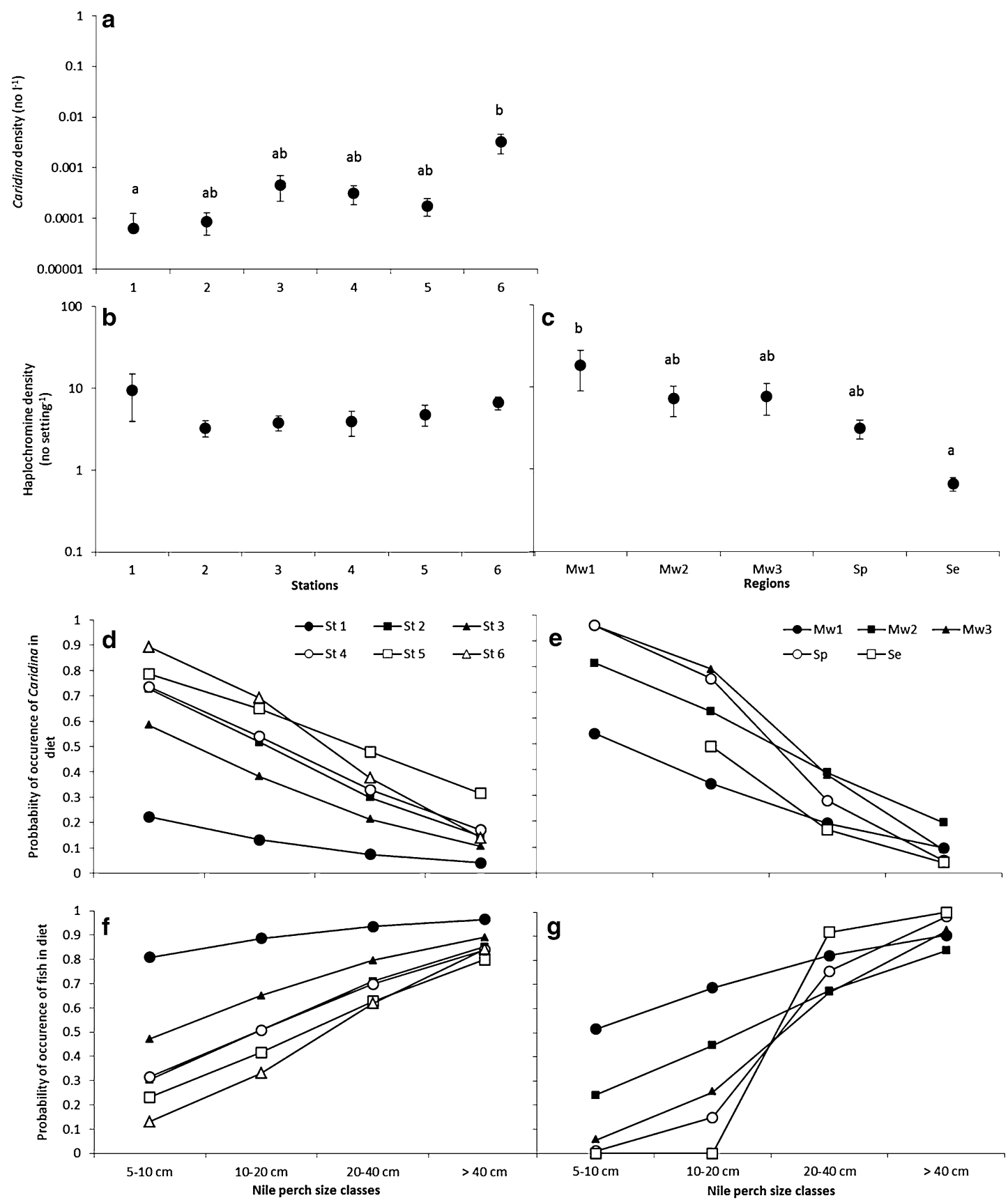

Fig. 6 Spatial variation in prey density and diet composition of Nile perch size classes on a local scale in Mwanza Gulf and on a regional scale between Mwanza Gulf, Speke Gulf and in Sengerema. a Mean Caridina densities and standard errors. Identical letters above means and standard errors in figures a-c indicate non-significant differences between densities in a multiple comparison test $(P \geq 0.05)$, b-c mean haplochromine densities (CPUE) and standard errors, $\mathbf{d}-\mathbf{e}$ probability of occurrence of Caridina prey found in the diet of different Nile perch size classes and $\mathbf{f}-\mathbf{g}$ probability of occurrence of fish prey found in the diet of Nile perch size classes. Abbreviations used for indicating Mwanza stations and regions as in the caption of Fig. 3. For position of sampling stations see Fig. 1 
recovery in the Gulf (Witte et al., 2000, 2007; KisheMachumu, 2012). Results of nightly experimental surface trawling (up to $3.5 \mathrm{~m}$ deep), carried out throughout all seasons in 2010-2011 in the Mwanza Gulf, confirm the high densities of haplochromines and Nile perch of $<5 \mathrm{~cm}$ in waters of $<7 \mathrm{~m}$ depth, both of which were three times higher than in deeper parts of the Gulf (I. J. M. Cornelissen, unpublished data). This suggests that the Mwanza Gulf is a wellsuited habitat for small-sized fish. The now abundant haplochromines in shallow, inshore areas, as we found in the Mwanza Gulf, probably provide a good source of prey for juvenile Nile perch (Hecky et al., 2010; Taabu-Munyaho et al., 2013) and may increase survival and recruitment rates. The higher densities of juvenile Nile perch during the wet seasons in our study may be related to increased survival of recruits. We did not find evidence for increased spawning activity as we did not observe increased densities of mature Nile perch prior to the observed peak of juveniles. Seasonally higher densities in shallow areas can also be caused by Nile perch migrating from deeper waters during the wet seasons when the water column becomes stratified and hypoxic near the bottom (Taabu-Munyaho et al., 2013). However, we only found seasonal variation in Nile perch densities of $5-10 \mathrm{~cm}$ and therefore we postulate that the seasonal variation is related to survival of recruits.

\section{Regional scale}

On a regional scale, Nile perch densities in the Mwanza Gulf were 10 and 40 times higher than in the Speke Gulf and Sengerema respectively. In contrast, during the Nile perch boom, from 1987 to 1990, Nile perch densities were homogeneous across the regions of Mwanza and Speke Gulf (Goudswaard et al., 2008). More recent stock assessments through bottom trawling and catch assessments of Nile perch in the Tanzanian part of the lake from 1997 to 2002 showed that Nile perch aggregated on a very local and temporal scale in shallow and deep waters and at different depths of the water column (Mkumbo, 2002; Mkumbo et al., 2007). However, on a large spatial scale, there was no consistent pattern in Nile perch densities between the east, west and south side of the Tanzanian part of the lake or between different depths up to $50 \mathrm{~m}$ (Mkumbo, 2002; Mkumbo et al., 2007). In contrast, lake-wide acoustic surveys from 2007 to 2010 showed a seasonal spatial variation in Nile perch distributions, with higher densities in shallow waters and in the upper layers of the water column as a result of vertical and horizontal migrations related to oxygen (Taabu-Munyaho et al., 2013).

The overall low Nile perch densities in Sengerema were mostly the result of very low densities of juvenile Nile perch, in contrast to the Mwanza Gulf, with relatively high densities of small Nile perch between 5 and $20 \mathrm{~cm}$ [about 2.5-9.5 months old recruits (Hughes, 1992)]. Length-frequency distributions in the Tanzanian part of Lake Victoria showed that recruitment was higher in productive, sheltered, shallow bays (Mkumbo, 2002). Therefore, we postulate that the productive shallow, sheltered habitats of the Mwanza Gulf may act as a nursery where larvae and juvenile Nile perch have higher survival rates than in Speke Gulf and in Sengerema.

Factors determining Nile perch distributions

Data on a regional scale was of a lower resolution than on a local scale because of lower sampling frequency in Speke Gulf and Sengerema during the study period. Yet, we found that most environmental drivers acted similarly on Nile perch densities on both scales despite spatial differences in densities (Fig. 5). This indicates that the resolution of the data was adequate to observe the main effects on Nile perch distribution patterns. In addition, environmental drivers acted similarly on Nile perch size classes, except on large Nile perch of $>40 \mathrm{~cm}$ (Fig. 5). On a local and regional scale, maximum depth best predicted Nile perch densities of all size classes. Depth can be considered as a habitat proxy, since it correlates strongly with other environmental variables such as oxygen content, temperature, and visibility. In Lake Victoria oxygen and temperature decrease with depth, whereas visibility increases with depth (Hecky, 1994; Silsbe, 2004; Silsbe et al., 2006; Cornelissen et al., 2014). These and other habitat characteristics related with depth may have similar or contrasting effects on Nile perch densities and thus might explain the often non-linear nature between maximum depth and Nile perch densities. The decreasing densities of Nile perch with depth on a local scale and the increasing densities of Nile perch $>40 \mathrm{~cm}$ with depth on a regional scale we 
found in our study (Fig. 5), confirms the importance of shallow habitats for juvenile Nile perch (Mkumbo, 2002).

Surprisingly, on both local and regional scales, we did not find strong relationships between Nile perch densities and oxygen concentrations as was found in other studies in Lake Victoria (Wanink et al., 2001; Mkumbo, 2002; Goudswaard et al., 2011; Njiru et al., 2012; Nyboer \& Chapman, 2013; Taabu-Munyaho et al., 2013). On a local scale we did not find any relationships between oxygen concentration and Nile perch density (Fig. 5), despite studies in the Mwanza Gulf during the 1980s that showed the importance of oxygen for explaining Nile perch distribution (Wanink et al., 2001; Goudswaard et al., 2011), especially in water deeper than $15 \mathrm{~m}$ (Wanink et al., 2001). In our study in the Mwanza Gulf, low oxygen levels were seasonally related to the rainy season when stratification was strongest and spatially related to deep water. Most probably low oxygen conditions and hypoxia were less severe during our study in the Mwanza Gulf compared to the studies in the 1980s. In 1987-1988, persistent hypoxia near the bottom occurred over 3-5 months in waters as shallow as $6-20 \mathrm{~m}$ in the Mwanza Gulf (Wanink et al., 2001), whereas during our sampling period, stratification in the Mwanza gulf was weak and probably fluctuating on a daily basis (Cornelissen et al., 2014). This might also explain the apparent absence of the interaction between depth and oxygen concentration as described by Goudswaard et al. (2011). On a regional scale, oxygen concentration related positively with Nile perch densities of size classes between 5 and $20 \mathrm{~cm}$. This positive relationship was only visible when oxygen concentrations were above $8 \mathrm{mg}^{-1}$ (Fig. 5). Such a threshold value seems very high as critical oxygen levels for Nile perch are much lower (i.e., are between 2.5 and $3 \mathrm{mg}^{-1}$ ) (Kaufman \& Ochumba, 1993; Wanink et al., 2001). For fish of $20-40 \mathrm{~cm}$, densities were even negatively related with oxygen. Most likely the relationship between small Nile perch and oxygen results from the high densities of small Nile perch in the shallow waters of the Mwanza Gulf, which happens to be more oxygenated than deeper waters.

We found that, both on a regional and local scale, densities of small Nile perch size classes between 5 and $20 \mathrm{~cm}$ increased with temperature with a local optimum between 24 and $26^{\circ} \mathrm{C}$. In Lake Nabugabo, a similar optimal temperature range for Nile perch
$>20 \mathrm{~cm}$ (i.e., $25-26^{\circ} \mathrm{C}$ ) was found (Nyboer \& Chapman, 2013). Except for large Nile perch $>40 \mathrm{~cm}$, we found that, on a regional scale, temperature positively affected the densities of all Nile perch size classes. Temperature most likely affected densities indirectly through high recruitment and juvenile survival during the warmer, productive, wet seasons in the Mwanza Gulf. This seasonal effect of temperature on small Nile perch only, and the non-linear, positive nature of the relationship might be the reason why other studies found contrasting results with regard to the relationship between temperature and Nile perch densities (Getabu et al., 2003; Goudswaard et al., 2011; Nyboer \& Chapman, 2013).

Visibility as measured by Secchi depth had less influence on Nile perch distributions than maximum depth on both regional and local scales. As visibility was strongly related to maximum depth, it probably did not directly relate to Nile perch densities.

Prey densities were not strongly correlated with Nile perch densities, indicating that prey densities do not drive Nile perch distributions and that Nile perch is an opportunistic predator. However, prey type and densities varied spatially and did influence Nile perch diet on a local and regional spatial scale, corroborating the opportunistic nature of Nile perch predation patterns. Nile perch of all sizes fed predominantly on haplochromines in shallow water of $<10 \mathrm{~m}$ in the Mwanza Gulf where haplochromine densities were high. This confirms that Nile perch is switching back to a haplochromine-based diet in these areas (Kishe-Machumu et al., 2012). Largersized Nile perch of $>40 \mathrm{~cm}$ ate haplochromines regardless of their abundance. It seems that large Nile perch do not follow their prey into the Mwanza Gulf despite their preference for fish, as densities of large Nile perch were low in the Mwanza Gulf where densities of haplochromines were high. In deeper waters of the Mwanza Gulf ( $>20 \mathrm{~m}$ ), the whole of Speke Gulf and in Sengerema small Nile perch of size classes between 5 and $20 \mathrm{~cm}$ fed on Caridina shrimp. Within the Mwanza Gulf, high Caridina densities in deep waters were related to a high proportion of shrimp in the Nile perch diet. This indicates that small-sized Nile perch opportunistically prey heavily on shrimp when available at high densities, as suggested by Goudswaard et al. (2011). However, at lower shrimp densities within 
the Mwanza Gulf, small Nile perch accordingly ate less shrimp and more of the abundant haplochromines. Downing et al. (2013) propose that growth and survival rates of Nile perch are affected by their specific diets of shrimp or haplochromines and that therefore diets may influence size distributions independent from fishery effects, thus affecting conclusions from size-based fishery assessments. However, strong, lake-wide effects on Nile perch size distributions because of specific diets are not to be expected, because of the high local variation in diets and prey densities and the opportunistic feeding habits of Nile perch. These will at most increase the variability in size at age of Nile perch cohorts.

\section{Conclusion}

We found that Nile perch distributions were heterogeneous on a local and regional scale. Maximum depth and temperature were the most important environmental drivers of Nile perch densities, acting similarly on both spatial scales. Relationships between diet and prey densities acted on smaller spatial scales and may influence growth and survival rates locally. This study emphasize the important role of habitat and season on Nile perch distribution patterns, especially of juvenile Nile perch. Changes and variation in environmental driving factors should be considered when interpreting developments in the Nile perch stock and the impact of fisheries when implementing management strategies.

Acknowledgments This work is part of the integrated project
"Exploitation or eutrophication as threats for fisheries?
Disentangling social and ecological drivers of ecosystem
changes in Lake Victoria (SEDEC)", supported by the
Netherlands Organization for Scientific Research (NWO/
WOTRO) grant number W01.65.304.00. We thank Koos (J.)
Vijverberg for his supervision, advise, and comments on this
manuscript. We thank Andrea Downing for her comments. We
thank Klaas Gerber, Alex Mangassa, Gerardi Rajabu, Paulo and
Emma for their valuable field assistance and support and all
enthusiastic M.Sc. students involved in the data collection for
this manuscript. Special thanks to the Tanzanian Fisheries
Research Institute (TAFIRI) in Mwanza for providing
laboratory space and use of field equipment during this research.

Open Access This article is distributed under the terms of the Creative Commons Attribution License which permits any use, distribution, and reproduction in any medium, provided the original author(s) and the source are credited.

\section{References}

Akiyama, T., A. A. Kajumulo \& S. Olsen, 1977. Seasonal variation of plankton and physicochemical condition in Mwanza Gulf, Lake Victoria. Bulletin of Freshwater Fisheries Research Laboratory 27: 48-61.

American Public Health Association, 2005. Standard methods for the examination of water and wastewater, 18th ed. American Public Health Association, Washington, DC.

Balirwa, J. S., C. A. Chapman, L. J. Chapman, I. G. Cowx, K. Geheb, L. Kaufman, R. H. Lowe-McConnell, O. Seehausen, J. H. Wanink, R. L. Welcomme \& F. Witte, 2003. Biodiversity and fishery sustainability in the Lake Victoria basin: an unexpected marriage? BioScience 53: 703-715.

Chapman, L. J., C. A. Chapman, F. G. Nordlie \& A. E. Rosenberger, 2002. Physiological refugia: swamps, hypoxia tolerance and maintenance of fish diversity in the Lake Victoria region. Comparative Biochemistry and Physiology Part A 133: 421-437.

Cornelissen, I. J. M., G. Silsbe, J. A. J. Verreth, E. van Donk \& L. A. J. Nagelkerke, 2014. Dynamics and limitations of phytoplankton biomass along a gradient in Mwanza Gulf, southern Lake Victoria (Tanzania). Freshwater Biology 59: 127-141.

Cózar, A., M. Bruno, N. Bergamino, B. Úbeda, L. Bracchini, A. M. Dattilo \& S. A. Loiselle, 2012. Basin-scale control on the phytoplankton biomass in Lake Victoria, Africa. PLoS ONE 7: 1-9.

Downing, A. S., E. H. van Nes, K. E. van de Wolfshaar, M. Scheffer \& W. M. Mooij, 2013. Effects of resources and mortality on the growth and reproduction of Nile perch in Lake Victoria. Freshwater Biology 58: 828-840.

Getabu, A., R. Tumwebaze \& D. N. MacLennan, 2003. Spatial distribution and temporal changes in the fish populations of Lake Victoria. Aquatic Living Resources 16(3): 159-165.

Goudswaard, K., F. Witte \& E. F. B. Katunzi, 2008. The invasion of an introduced predator, Nile perch (Lates niloticus, L.) in Lake Victoria (East Africa): chronology and causes. Environmental Biology of Fishes 81: 127-139.

Goudswaard, K., E. F. B. Katunzi \& F. Witte, 2011. Distribution of Nile perch Lates niloticus in southern Lake Victoria is determined by depth and dissolved oxygen concentrations. African Journal of Aquatic Science 36: 147-153.

Hecky, R. E., 1993. The eutrophication of Lake Victoria. Verhandlungen der internationalen Vereinigung für Limnologie 25: 39-48.

Hecky, R. E., 1994. Deoxygenation of the deep water of Lake Victoria, East Africa. Limnology and Oceanography 39: 1476-1481.

Hecky, R. E., R. Mugidde, P. S. Ramlal, M. R. Talbot \& G. W. Kling, 2010. Multiple stressors cause rapid ecosystem change in Lake Victoria. Freshwater Biology 55: 19-42.

Hughes, N. F., 1992. Growth and reproduction of the Nile perch, Lates niloticus, an introduced predator, in the Nyanza Gulf, Lake Victoria, East Africa. Environmental Biology of Fishes 33: 299-305.

Katunzi, E. F. B., W. L. T. van Densen, J. H. Wanink \& F. Witte, 2006. Spatial and seasonal patterns in the feeding habits of juvenile Lates niloticus (L.), in the Mwanza Gulf of Lake Victoria. Hydrobiologia 568: 121-133. 
Kaufman, L., 1992. Catastrophic change in species-rich freshwater ecosystems. Bioscience 42: 846-858.

Kaufman, L. \& P. B. O. Ochumba, 1993. Evolutionary and conservation biology of cichlid fishes as revealed by faunal remnants in northern Lake Victoria. Conservation Biology 7: 719-730.

Kishe-Machumu, M. A., 2012. Inter-guild differences and possible causes of the recovery of cichlid species in Lake Victoria, Tanzania. PhD. thesis, Leiden University.

Kishe-Machumu, M. A., F. Witte, J. H. Wanink \& E. F. B. Katunzi, 2012. The diet of Nile perch, Lates niloticus (L.) after resurgence of haplochromine cichlids in the Mwanza Gulf of Lake Victoria. Hydrobiologia 682: 111-119.

Kolding, J., P. A. M. van Zwieten, O. C. Mkumbo, G. Silsbe \& R. E. Hecky, 2008. Are the Lake Victoria fisheries threatened by exploitation or eutrophication? Towards an ecosystembased approach to management. In Bianchi, G. \& H. R. Skjoldal (eds), The Ecosystem Approach to Fisheries. CABI, Wallingford, uk and FAO, Rome: 309-354.

Kolding, J., M. Medard, O. C. Mkumbo \& P. A. M. van Zwieten, 2014. Status, trends and management of the Lake Victoria fisheries. In: Welcomme, R. L., J. Jorgensen-Valbo \& A. $\mathrm{S}$. Halls (eds) Inland fisheries evolution and managementcase studies from four continents. FAO Fisheries and Aquaculture Technical Paper No.579, Rome, 1-19.

Matsuishi, T., L. Muhoozi, O. C. Mkumbo, Y. Budewa, M. Njiru, A. Asila, A. Othina \& I. G. Cowx, 2006. Are the exploitation pressures on the Nile perch fisheries resources of Lake Victoria a cause for concern? Fisheries Management and Ecology 13(1): 53-71.

Mkumbo, O. C., 2002. Assessment and management of Nile perch (Lates niloticus L.) stocks in the Tanzanian waters of Lake Victoria. PhD thesis, University of Hull.

Mkumbo, O. C., P. Nsinda, C. N. Ezekiel, I. G. Cowx \& M. Aeron, 2007. Towards sustainable exploitation of Nile perch consequential to regulated fisheries in Lake Victoria. Aquatic Ecosystem Health and Management 10: 449-457.

Njiru, M., C. Nyamweya, J. Gichuki, R. Mugidde, O. C. Mkumbo \& F. Witte, 2012. Increase in anoxia in Lake Victoria and its effects on the fishery. In Padilla, P. (ed.), Anoxia. InTech, Rijeka: 99-128.

Nyboer, E. A. \& L. J. Chapman, 2013. Movement and home range of introduced Nile perch (Lates niloticus) in Lake Nabugabo, Uganda: implications for ecological divergence and fisheries management. Fisheries Research 137: 18-29.

Ochumba, P. B. O., 1990. Massive fish kills within the Nyanza Gulf of Lake Victoria, Kenya. Hydrobiologia 208: 93-99.

Ogutu-Ohwayo, R., 1999. Deterioration in length-weight relationships of Nile perch, Lates niloticus L. in lakes Victoria, Kyoga and Nabugabo. Hydrobiologia 403: 81-86.

Ogutu-Ohwayo, R., 2004. Management of the Nile perch, Lates niloticus fishery in Lake Victoria in light of the changes in its life history characteristics. African Journal of Ecology 42: 306-314.

Paterson, J. A. \& L. J. Chapman, 2009. Fishing down and fishing hard: ecological change in the Nile perch of Lake Nabugabo, Uganda. Ecology of Freshwater Fish 18: 380-394.
Pauly, D., 1981. The relationships between gill surface area and growth performance in fish: a generalization of von Bertalanffy's theory of growth. Berichte der Deutschen Wissenchaftlichen Kommission für Meeresforschung 28: 251-282.

Pauly, D., 1984. A mechanism for the juvenile-to adult transition in fishes. Journal du Conseil International pour l'Exploration de la Mer 41: 280-284.

Pringle, R. M., 2005. The origins of the Nile Perch in Lake Victoria. Bioscience 55: 780-787.

Schofield, P. J. \& C. A. Chapman, 2000. Hypoxia tolerance of introduced Nile perch: implications for survival of indigenous fishes in the Lake Victoria basin. African Zoology 35: 35-42.

Seehausen, O., J. J. M. van Alphen \& F. Witte, 2003. Implications of eutrophication for fish vision, behavioral ecology and species coexistence. In Chrisman, T., L. Chapman \& C. Chapman (eds), Aquatic Conservation and Management in Africa. University of Florida Press, Gainsville: 266-287.

Silsbe, G. M., 2004. Phytoplankton production in Lake Victoria, East Africa. MSc thesis, University of Waterloo.

Silsbe, G. M., R. E. Hecky, S. J. Guildford \& R. Mugidde, 2006. Variability of chlorophyll $a$ and photosynthetic parameters in a nutrient-saturated tropical great lake. Limnology and Oceanography 51: 2052-2063.

Sitoki, L., C. Ezekiel, F. Wanda, O. C. Mkumbo \& B. E. Marshall, 2010. The environment of Lake Victoria (East Africa): current status and historical changes. International Review of Hydrobiology 95: 209-223.

Taabu-Munyaho, A., R. J. Kayanda, I. Everson, T. B. Grabowski \& G. Marteindóttir, 2013. Distribution and exploitation of Nile perch Lates niloticus in relation to stratification in Lake Victoria, East Africa. Journal of Great Lakes Research 39: 466-475.

Talling, J. F., 1966. The annual cycle of stratification and phytoplankton growth in Lake Victoria (East Africa). Internationale Revue der gesamten Hydrobiologie 51: 545-621.

Wanink, J. H., J. J. Kashindey, K. Goudswaard \& F. Witte, 2001. Dwelling at the oxycline: does increased stratification provide a predation refugium for the Lake Victoria sardine Rastrineobola argentea? Freshwater Biology 46: 75-85.

Witte, F. \& W. L. T. van Densen, 1995. Fish stocks and fisheries of Lake Victoria; a handbook for field observations. Samara, Cardigen.

Witte, F., T. Goldschmidt, J. H. Wanink, M. van Oijen, K. Goudswaard, E. Witte-Maas \& N. Witte-Maas, 1992. The destruction of an endemic species flock quantitative data on the decline of the haplochromine cichlids of Lake Victoria. Environmental Biology of Fishes 34: 1-28.

Witte, F., B. S. Msuku, J. H. Wanink, O. Seehausen, E. F. B. Katunzi, P. C. Goudswaard \& T. Goldschmidt, 2000. Recovery of cichlid species in Lake Victoria: an examination of factors leading to differential extinction. Reviews in Fish Biology and Fisheries 10: 233-241.

Witte, F., J. H. Wanink, M. Kishe-Machumu, O. C. Mkumbo, P. C. Goudswaard \& O. Seehausen, 2007. Species distinction and the biodiversity crisis in Lake Victoria. Transactions of the American Fisheries Society 136: 1146-1159. 